\title{
Optimization of machining parameters during end milling of super alloys using grey based taguchi method coupled with entropy measurement technique
}

Reddy SREENIVASULU, Chalamalasetti Srinivasa RAO

DOI: 10.30464/jmee.2020.4.1.47

Cite this article as:

Sreenivasulu R., Rao Ch. S. Optimization of machining parameters during end milling of super alloys using grey based taguchi method coupled with entropy measurement technique. Journal of Mechanical and Energy

Engineering, Vol. 4(44), No. 1, 2020, pp. 47-56.

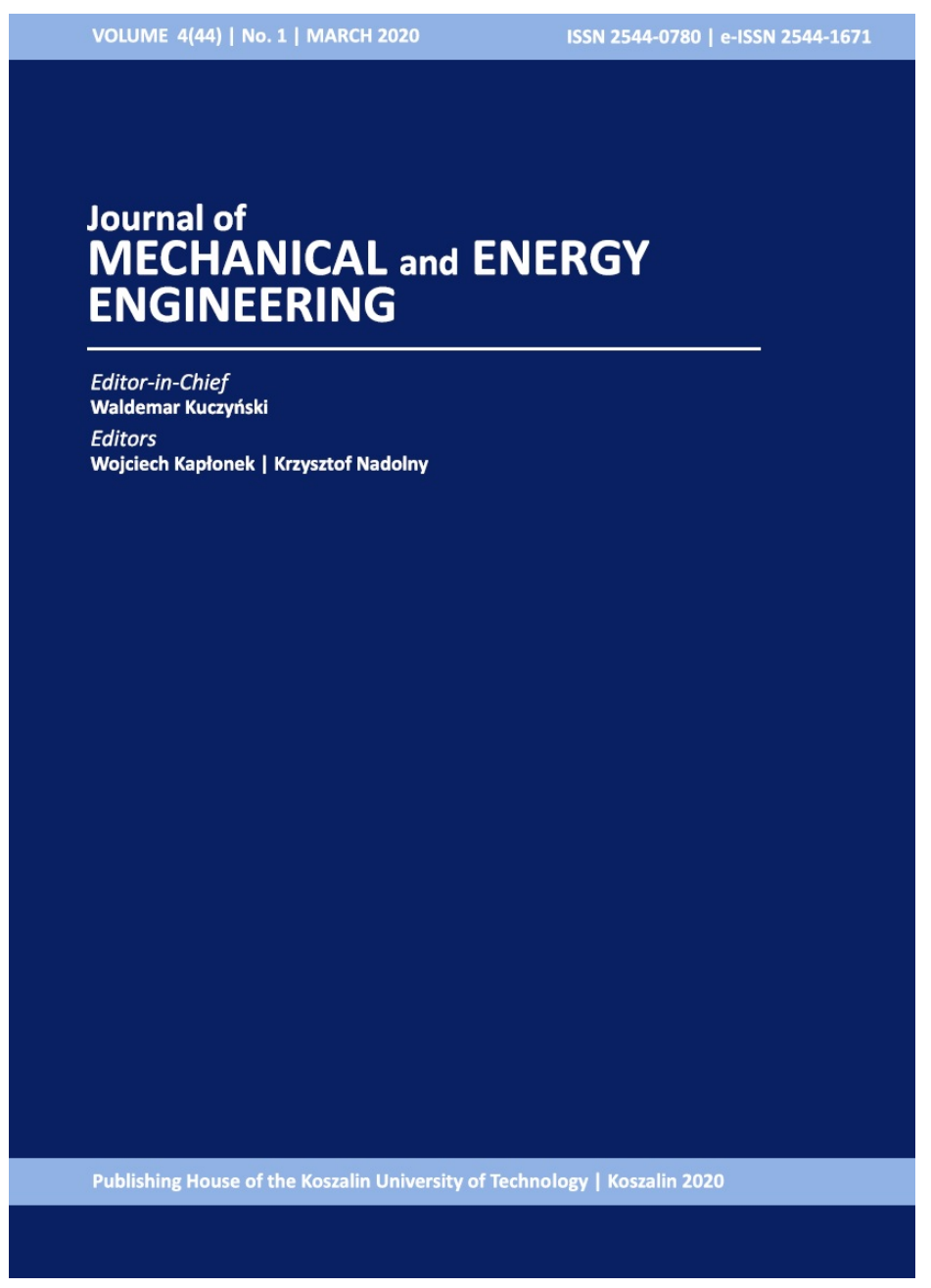

Journal of Mechanical and Energy Engineering

Website: jmee.tu.koszalin.pl

ISSN (Print): 2544-0780

ISSN (Online): 2544-1671

Volume: 4(44)

Number: 1

Year: 2020

Pages: 47-56

Article Info:

Received 5 March 2020

Accepted 13 March 2020

\section{Open Access}

This article is distributed under the terms of the Creative Commons Attribution 4.0 (CC BY 4.0) International License (http://creativecommons.org/licenses/by/4.0/), which permits unrestricted use, distribution, and reproduction in any medium, provided you give appropriate credit to the original author(s) and the source, provide a link to the Creative Commons license, and indicate if changes were made. 


\title{
OPTIMIZATION OF MACHINING PARAMETERS DURING END MILLING OF SUPER ALLOYS USING GREY BASED TAGUCHI METHOD COUPLED WITH ENTROPY MEASUREMENT TECHNIQUE
}

\author{
Reddy SREENIVASULU ${ }^{1 *}$, Chalamalasetti Srinivasa RAO ${ }^{2}$ \\ ${ }^{1 *}$ R.V.R \& J.C.College of Engineering (Autonomous), Department of Mechanical Engineering, \\ Guntur, Andhra Pradesh, e-mail: rslu1431@gmail.com \\ ${ }^{2}$ University College of Engineering (Autonomous), Department of Mechanical Engineering, \\ Andhra University, Visakhapatnam
}

(Received 5 March 2020, Accepted 13 March 2020)

\begin{abstract}
High-quality products include those with better surface quality and texture, close dimensional tolerances and form accuracies at precise level, increase fatigue life and burr-free. Burr formation is one of the most common inevitable facts occurring in all material removal processes, reduces assembly and machined part quality. But, burr formation during milling is a more complex mechanism compare to remaining machining burrs and leads to numerous difficulties during the deburring process. To prevent this, one should optimize the combination of cutting parameters during machining itself. In order to build up a link between quality and productivity and to attain the same in the cost-effective way, the present work concentrate on multi objective optimization of $\mathrm{CNC}$ end milling process parameters. Multiple performance characteristics with respect to surface quality and performance index like assembly work have been put up, to assess an equivalent single quality index (called grey relational grade) has been optimized finally by Grey based Taguchi method. After that priority weight of individual quality and performance attributes has been estimated by entropy measurement technique on the basis of relative significance and check the feasibility of the proposed technique has been demonstrated in this context.
\end{abstract}

Keywords: CNC end milling, inconel 718 super alloy, burr height, surface roughness, grey based Taguchi method, entropy measurement

\section{INTRODUCTION}

Nowadays, machining of nickel based super alloy parts is one of the big challenges in the manufacturing industry because of a huge demand for the products made by super alloys. The main feature of $\mathrm{Fe}, \mathrm{Ni} \&$ Co based super alloys due to its austenitic structure brings high ductility and work hardening, producing a gummy machining behavior. In addition, these are designed for high temperature applications remain strong at the generating temperatures while metal cutting operations, temperature stays always much high on the cutting edge. Inconel 718 is widely used in aircraft gas turbine, reciprocating engines, space vehicles, nuclear power plants, chemical application, high temperature fasteners, springs, rings and pulp and paper industry [1]. Milling process is the machining process to form three dimensional surfaces from variety of materials. Burr formation is one of the basic problems that reduces the surface quality and also machinability of parts by various metal cutting operations. Burr size influences more while assemble intricate parts and damages the part edges to cause accidents to workers, if it is a miniature level then deburring process would becomes complex and increase the indirect cost $[2,3]$. The present paper focused on experimental study based on Taguchi's method carried out to investigate the effect of parameters namely spindle speed, feed rate and depth of cut on burr height and thickness formed in end milling operation apart from this surface roughness along the slot also examined. Analysis of variances 
has been carried out to find the percentage of contribution of each parameter on burr height and its thickness. Finally grey relational analysis has been carried out for obtaining the parameter setting regarding minimum burr height and thickness. Researchers have suggested techniques for reducing burr by changing process parameters, such as lowering depth of cut, increasing cutting speed $[4,5]$.

\section{LITERATURE REVIEW}

In general surface conditions of a manufacturing or machining metal part directly influence the processing and end use of that part [6]. The machinability of materials refers to the ease with which a metal can be machined permitting the removal with satisfactory finish at low cost. The machinability of super alloys is not only related with material property, but also affected by the machining condition. However, seldom research has been focused on the machinability of Inconel 718 super alloy leads to the confusion of selection proper cutting parameters for machining process [7]. The Inconel-718 alloy is a group of nickel-based super alloys which is identified in some specialized applications especially on the turbine and aerospace component parts. This material is employed in this field due to its excellent properties such as good resistance to corrosion and high chemical as well as physical strength against elevated temperatures [8]. Gopala Rao Thellaputtaa etal [9] reviewed in detail about the development, classification, applications of Nickel based super alloys. And also presents processing of Nickel based super alloys including microstructure, tool materials, and effect of cutting parameters, and use of coolant supply and the integrity of machined surface. S. S. Karidkar et al. [10] discussed in their work about utilization of Wire Electrical Discharge Machining (WEDM) technology, which is challenging for modern manufacturing industries to fulfill the customers need using Inconel 718. M Manohar et al. [11] used Box Behnken design approach to plan the experiments for turning Inconel 718 alloy with an overall objective of optimizing the process to yield higher metal removal, better surface quality and lower cutting forces using Response Surface methodology (RSM). Miroslav Janos et al. [12] described on milling possibilities of nickel alloy Inconel 718. In the beginning the authors described the use of nickel alloys in industry and division of nickel alloys. Also, described on tests of machinability by recommended cutting materials for nickel alloys in milling. Xiaohong $\mathrm{Lu}$ et al. [13] conducted experiments based on center composite rotatable design (CCRD and chosen depth of cut, spindle speed and feed rate for their experimentation. To check the adequacy of proposed models they considered statistical techniques such as ANOVA and concluded finally depth of cut on surface roughness in micro-milling was a critical influence factor. The review of literature describes that the earlier researchers concentrated on different worked out experimental models developed by previous researchers gave the correlations among various cutting parameters during milling operations. Apart from surface quality, study on burr formation has been found in a limited extent. But it has been identified that optimization is highlighted a single objective function. In a multi response process, it may arise the optimization of a single response may harm quality for rest of the output responses. Therefore it is advised to alter the individual objective function into correspondent single objective function; it is possible only by assigning individual response weights depending on their relative prominence. It seems that there is no particular guideline for this assignment of weights for chosen output responses and entirely depends on decision maker, so it may cause to change the optimality setting of parameters. In view of the above consideration the present investigations deals with the application of grey based Taguchi method with quality loss function for optimization of burr height, thickness and surface roughness during $\mathrm{CNC}$ slot milling process with integration of entropy measurement methodology to evaluate priority of individual weights of responses based on statistical data acquired from experimental values.

\section{BURR FORMATION}

An unwanted projection of material formed during any machining operation, termed as burr as a part size errors. Burr is plastically deformed material, generated on the part edge during cutting or shearing [14].

\subsection{Burr definitions and classification}

Burr formation is one of the critical issues at present in all manufacturing industries, which should be avoided or at least minimized. Out of all the parameters, the burr height and thickness are used to determine the burr removal difficulties by numerous authors. Miniature burrs not visible to the naked eye, therefore a correct selection of machining parameters and their setting levels are very important in order to minimize the occurrence of burr formation and possibly improve the surface quality and dimensional tolerances to attain proper assembly. Milling burrs are generated when the cutter enters and exits on the work parts. Hashimura et al [15] proposed a nomenclature to categorize the formation of milling burrs with respect to their position and cutting mechanism for exit burrs. In some particular conditions large burrs are also formed along the cutting direction and their height is consistent and approximately equal to the depth of cut. In some cases, a burr is separated at its thinnest part, leaving only a small portion adhered to the machined 
part surface. The burr height in this case is much smaller than the depth of cut.

Figure 1 summarizes the different burrs encountered during slot milling: the entrance burrs are smallest in size; the top burrs, the entrance and the exit burrs along the down milling side are on a medium scale comparatively. Exit burrs are the largest burrs considering the smaller size of entrance burrs and put more efforts to understand of those at the exit zone of the milling operation. Therefore, a series of experiments were conducted by varying different factors in sequence in order to observe variations in the exit burrs [17].

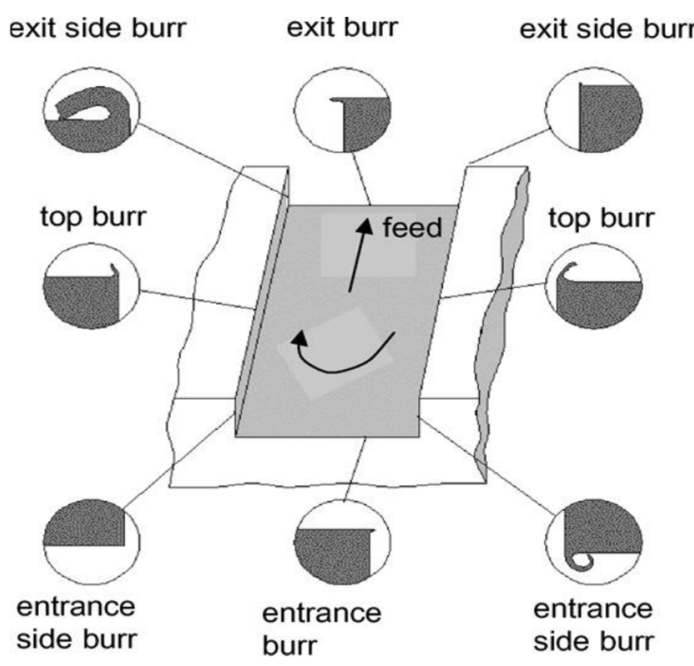

Fig. 1. Slot milling burrs [16]

\section{EXPERIMENTATION AS PER TAGUCHI DESIGN METHOD}

As per the Taguchi design of experimental plan based on beginning selection of parameters and their levels suitable orthogonal array was selected to do the experiments to investigate the influence of machining parameters on response characteristics. Basically the selection of orthogonal array is concerned with the total degree of freedom (DOF) of process parameters. The degree of freedom for the orthogonal array should be greater than or at least equal to that of the machining parameters. So, $L_{9}$ orthogonal array has been considered having degree of freedom equal to $(9-1=8) 8$ [14]. In this study, the experiments are carried out on a CNC vertical machining center (shown in Fig. 2) to perform $10 \mathrm{~mm}$ slots on Inconel 718 super alloy work piece of rectangular cross section with an average material hardness of $48 \mathrm{HRC}$ was selected to conduct slot milling operation. The specification of cutting insert and tool holder is CNMG 1204 08-MS-KC5525 and PCLNR 2020K12, respectively.

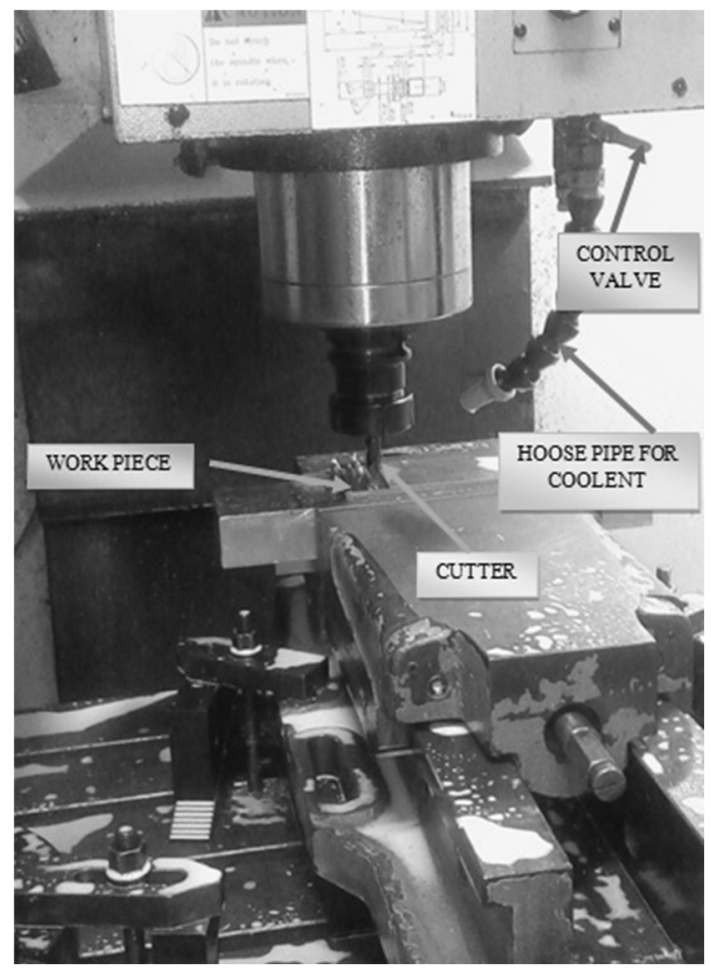

Fig. 2. Experimental set up

Furthermore the spindle speed $(A)$ in rpm, the feed rate $(B)$ in $\mathrm{mm} / \mathrm{rev}$ and depth of cut $(C)$ in $\mathrm{mm}$ are selected in three levels and controlled automatically with machine itself by writing in a computer assisted part programme. Each experiment was conducted in three times and the burr height is measured using profile projector in $\mathrm{mm}$ as unit and shown in Fig. 3, finally surface roughness is measured at five places on each slot then average of them in $\mu \mathrm{m}$ as unit using a surface analyzer of Surf Test-211 series (Mitutoyo) shown in Fig. 4. The experimental results according to $L_{9}$ orthogonal array and measured output responses are depicted in Table 1 .

Tab. 1. General characteristics of grinding conditions

\begin{tabular}{cccccc}
\hline $\begin{array}{l}\text { Exp. } \\
\text { No. }\end{array}$ & $\begin{array}{c}\text { Rotational } \\
\text { Speed }(A) \\
{[\mathrm{rpm}]}\end{array}$ & $\begin{array}{c}\text { Depth of } \\
\text { Cut }(B) \\
{[\mathrm{mm}]}\end{array}$ & $\begin{array}{c}\text { Feed } \\
\text { Rate }(C) \\
{[\mathrm{mm} / \mathrm{rev}]}\end{array}$ & $\begin{array}{c}\text { Burr } \\
\text { Height } \\
(B h) \\
{[\mathrm{mm}]}\end{array}$ & $\begin{array}{c}\text { Surface } \\
\text { Roughness } \\
(R a)[\mu \mathrm{m}]\end{array}$ \\
\hline 1 & 1000 & 0.75 & 0.06 & 5.75 & 5.86 \\
\hline 2 & 1000 & 1.00 & 0.09 & 8.75 & 6.07 \\
\hline 3 & 1000 & 1.50 & 0.12 & 5.90 & 4.54 \\
\hline 4 & 1500 & 0.75 & 0.09 & 9.00 & 7.05 \\
\hline 5 & 1500 & 1.00 & 0.12 & 3.50 & 0.43 \\
\hline 6 & 1500 & 1.50 & 0.00 & 8.00 & 0.69 \\
\hline 7 & 2000 & 0.75 & 0.12 & 2.50 & 0.99 \\
\hline 8 & 2000 & 1.00 & 0.06 & 5.50 & 0.29 \\
\hline 9 & 2000 & 1.50 & 0.09 & 6.50 & 0.32 \\
\hline
\end{tabular}




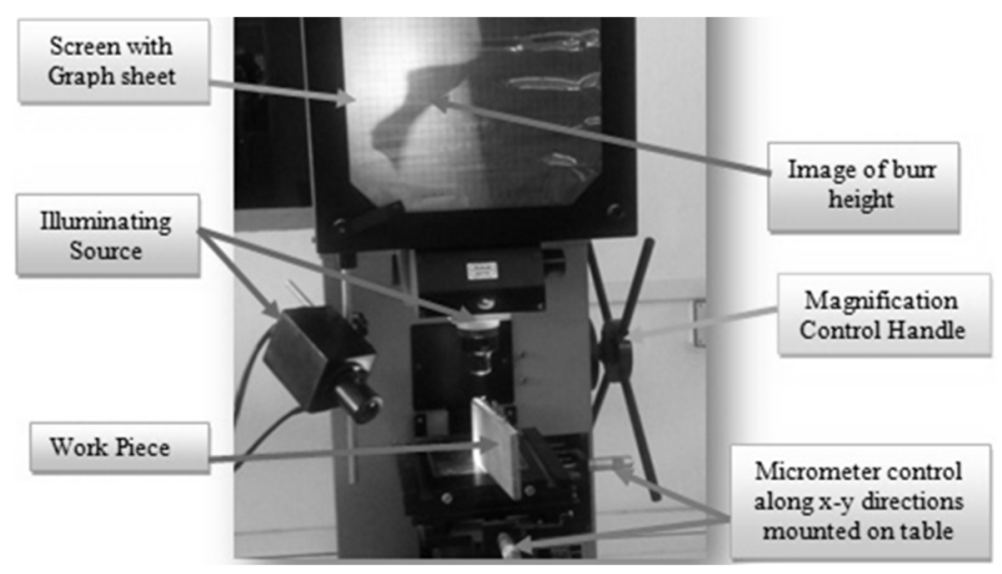

Fig. 3. Setup for burr height measurement

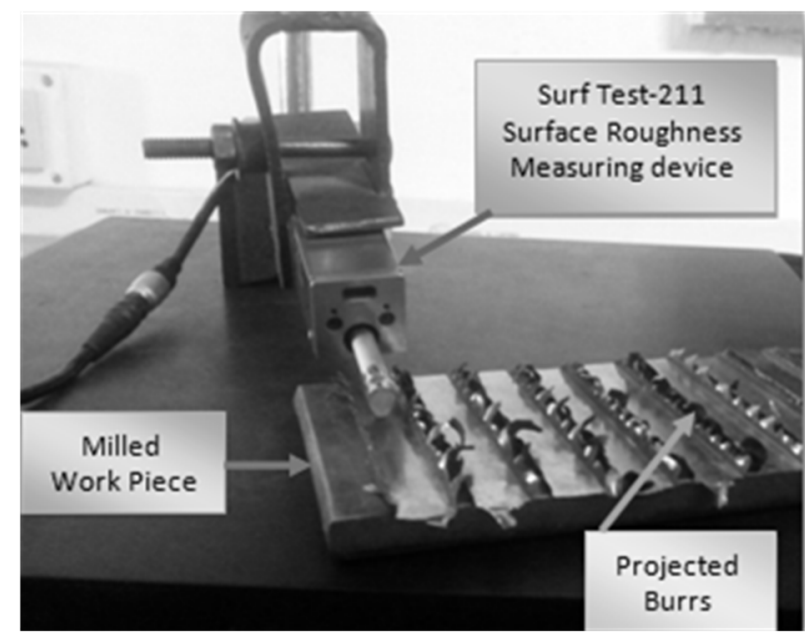

Fig. 4. Setup for surface roughness measurement

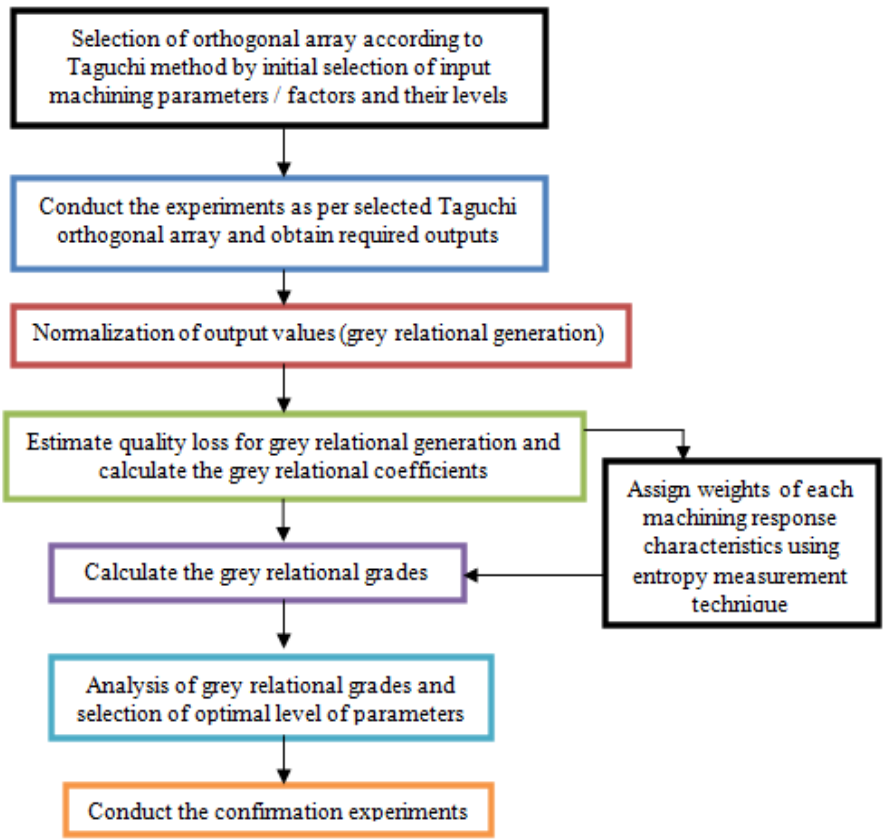

Fig. 5. Steps in proposed methodology 


\subsection{Proposed Methodology}

The grey system theory can be utilized to solve the confused interrelationships among the multiple responses efficiently. In a grey system part of the information is known and some is unknown. GRA is applied in optimization of process parameters in various machining operations with multiple-responses. In the grey relational analysis, the grey relational grade is employ to show the relationship among the data sequences. If the two sequences are similar, then the value of grey relational grade is equivalent to one. Therefore, if a particular comparability sequence is more important than the other comparability sequences to the reference sequence, then the grey relational grade for that comparability sequence and reference order will be much more than other grey relational grades. Entropy measurement can be apply to assign proper weightage of influenced parameters during machining, which helps to enhance the feasibility of the proposed method (shown in Fig. 5) while optimizing multi performance characteristics during end milling of Inconel 718 super alloy.

\subsection{Data pre-processing}

Data pre-processing was generally required because the range and unit of one data sequence may fluctuate from the other data sequence. Data preprocessing is a means of transporting the original sequence to a comparable sequence. If the target value of original order of data sequence is infinite, then it has a characteristic of the "larger is better" case. The original sequence can be normalized as follows:

$$
x_{i}^{*}(k)=\frac{x_{i}^{0}(k)-\min x_{i}^{0}(k)}{\max x_{i}^{0}(k)-\min x_{i}^{0}(k)},
$$

when the "smaller is better" case is a characteristic of the original order of sequence of data, then the original order of sequence should be normalized as follows:

$$
x_{i}^{*}(k)=\frac{\left[\max x_{i}^{0}(k)-x_{i}^{0}(k)\right]}{\left[\max x_{i}^{0}(k)-\min x_{i}^{0}(k)\right]},
$$

however, if there is a definite target value (desired value) to be achieved, the original sequence will be normalized in form:

$$
x_{i}^{*}(k)=1-\frac{\left|x_{i}^{0}(k)-x^{0}\right|}{\max x_{i}^{0}(k)-x^{0}} .
$$

The actual order of sequence can be simply normalized by the most basic methodology, i.e. let the values of original sequence are divided by the first value of the sequence:

$$
x_{i}^{*}(k)=\frac{x_{i}^{0}(k)}{x_{i}^{0}(1)},
$$

where, $\quad i=1 \ldots m ; k=1 \ldots n$. ' $m$ ' is the number of experimental data items and ' $n$ ' is the number of parameters, $x_{i}^{0}(k)$ denotes the original sequence, $x_{i}^{*}(k)$ the sequence after the data pre-processing, $\max x_{i}^{0}(k)$ the largest value of $x_{i}^{0}(k)$, the smallest value of $x_{i}^{0}(k)$ and $x_{i}^{0}$ is the desired value.

For data pre-processing in the grey relational analysis, all the responses are taken as the "smaller is better". The original (reference) sequences of each performance characteristics are transferred to comparable sequences by normalizing the experimental data. According to the Julong D [18] greater the normalized values of results corresponding to the better performance and the best normalized result should be equal to one and then the grey relational coefficients are found to be communicating the relationship between the ideal and the actual experimental results.

\subsection{Grey relational coefficient and grey relational grade}

In grey relational analysis, the measure of the relevancy between two systems or two sequences is defined as the grey relational grade. When only one sequence, $x^{0}(k)$, is available as the reference sequence, and all other sequences serve as comparison sequences, it is called a local grey relation measurement. After data pre-processing is carried out, the grey relation coefficient $\xi_{i}(k)$ for the $k^{\text {th }}$ performance characteristics in the $i^{\text {th }}$ experiment can be expressed as:

$$
\xi_{i}(k)=\frac{\Delta_{\min }+\xi \Delta_{\max }}{\Delta_{0 i}(k)+\xi \Delta_{\max }},
$$

Here $\Delta_{0 i}=\left\|x_{0}(k)-x_{i}(k)\right\|=$ difference of the absolute value $x_{0}(k) \& x_{i}(k) ; \Psi$ is the distinguishing coefficient $\quad 0 \leq \Psi \leq 1 ; \quad \Delta_{\text {min }}=\forall j^{\min } \in$ $i \forall k^{\text {min }}\left\|x_{0}(k)-x j(k)\right\|=$ the smallest value of $\Delta_{0 i}$; and $\quad \Delta_{\max }=\forall j^{\max } \in i \forall k^{\max }\left\|x_{0}(k)-x j(k)\right\|=$ largest value of $\Delta_{0 i}$. After averaging the grey relational coefficients, the grey relational grade $\gamma_{i}$ can be computed as:

$$
\begin{gathered}
\gamma_{i}=\frac{1}{n} \sum_{k=1}^{n} \xi_{i}(k), \\
\gamma_{i}=\frac{\sum_{k=1}^{n} w_{k} \xi_{i}(k)}{\sum_{k=1}^{n} w_{k}},
\end{gathered}
$$

The distinguishing coefficient $\xi$ can be substituted into Eq. 5 to deduce the grey relational coefficient. If all the process parameters are of equal weightage, then $\xi$ is 0.5 . The grey relational coefficients and grade values for each experiment of the $L 9$ orthogonal array are calculated by applying equations $5 \& 7$. The overall grey relational grades from the equation 
7 determined for three sets of response weightage such as in case 1 , equal priority has been given to burr height and surface roughness but in case 2, 75\% importance has been given to burr height and rest 25\% provided for surface roughness and similarly in case 3 , burr height assigned of 0.25 and surface roughness priority weight is 0.75 was considered which are depicted in Table 2. For each case optimal setting of input parameters calculated by average the overall grey relational grades corresponding to levels and included in the Table 3.

Tab. 2. Overall grey relational grade and predicted optimal setting

\begin{tabular}{cccc}
\hline Exp. & Case 1 & Case 2 & Case 3 \\
No. & $w_{l}=0.5$ & $w_{l}=0.75$ & $w_{l}=0.25$ \\
& $w_{2}=0.5$ & $w_{2}=0.25$ & $w_{2}=0.75$ \\
\hline 1 & 0.4388 & 0.4432 & 0.4399 \\
2 & 0.3555 & 0.4082 & 0.4092 \\
3 & 0.4658 & 0.4521 & 0.4511 \\
4 & 0.3333 & 0.4010 & 0.4010 \\
5 & 0.8624 & 0.8118 & 0.7323 \\
6 & 0.6327 & 0.6232 & 0.5803 \\
7 & 0.9141 & 0.7964 & 0.9068 \\
8 & 0.7002 & 0.7778 & 0.6471 \\
9 & 0.7197 & 0.7709 & 0.6500 \\
\hline
\end{tabular}

Tab. 3. Optimal setting of parameters case wise

\begin{tabular}{|c|c|c|c|}
\hline \multicolumn{4}{|c|}{ Case 1} \\
\hline \multirow[t]{2}{*}{ Levels } & \multicolumn{3}{|c|}{ Factors } \\
\hline & A & B & C \\
\hline 1 & 0.4200 & 0.5621 & 0.5905 \\
\hline 2 & 0.6094 & 0.6393 & 0.4695 \\
\hline 3 & 0.7780 & 0.6060 & 0.7474 \\
\hline \multicolumn{4}{|c|}{$\mathrm{A} 3 \mathrm{~B} 2 \mathrm{C} 3$} \\
\hline \multicolumn{4}{|c|}{ Case 2} \\
\hline & A & B & $\mathrm{C}$ \\
\hline 1 & 0.4345 & 0.5468 & 0.6147 \\
\hline 2 & 0.7817 & 0.6659 & 0.5267 \\
\hline 3 & 0.6120 & 0.6154 & 0.6867 \\
\hline \multicolumn{4}{|c|}{ A2B2C3 } \\
\hline \multicolumn{4}{|c|}{ Case 3} \\
\hline & A & $\mathrm{B}$ & $\mathrm{C}$ \\
\hline 1 & 0.4334 & 0.5825 & 0.5527 \\
\hline 2 & 0.5712 & 0.5762 & 0.6967 \\
\hline 3 & 0.7346 & 0.5604 & 0.4867 \\
\hline \multicolumn{4}{|c|}{$\mathrm{A} 3 \mathrm{~B} 1 \mathrm{C} 2$} \\
\hline
\end{tabular}

From Table 3 it is observed that the optimal setting of parameters for case 1 , case 2 and case 3 are A1B2C3, A2B2C3 and A1B1C2 respectively obtained from grey based Taguchi method, then we estimated the weightage of responses chosen in case 1 to 3 are feasible or not feasible can be found by applying entropy measurement technique in further sections.

\section{ENTROPY MEASUREMENT TECHNIQUE}

In theory of information, entropy is a quantitative measure of a physical system how it is disorder when subjected to external factors on it. As applying the phenomenon of this concept the weight measurement of individual factors which influence on the system. The effect of chosen attribute with a large entropy means that it has a more diversity to respond with a system which undergoes a process so the selected attribute has more significant to the response. Now days this method is used to decide the weights in grey relational analysis $[19,20]$. According to this method, the mapping function $f_{i}:[0,1] \rightarrow[0,1]$ is used in entropy should convince three situations: (1) $f_{i}(0)=0$, (2) $f_{i}(x)=f_{i}(1-x)$ and (3) $f_{i}(x)$ is monostimulantly increasing in the range $x \in(0,0,5)$, thus, the following function $w_{e}(x)$ can be used as the mapping function in entropy measure.

$$
w_{e}(x)=x e^{1-x}+(1-x) e^{x}-1 .
$$

The greatest amount of this function occurs at $x=0.5$ and the value is $\left(e^{0.5}-1\right)=0.6487$. In order to acquire the mapping result in the range $[0,1]$. It is defined as new entropy function:

$$
W \equiv \frac{1}{\left(e^{0.5}-1\right)} \sum_{i=1}^{m} w_{e}\left(x_{i}\right)
$$

Assume there is a order of sequence $\epsilon_{i}=$ $\left\{r_{i}(1), r_{i}(2), r_{i}(3), \ldots \ldots, r_{i}(n)\right\}$. Where $r_{i}(j)$ is the grey relational coefficient. Also it is noticed that $i=$ $1,2,3,4 \ldots, j=1,2,3, \ldots, n . m=$ Total number of conducted experiments as per Taguchi's $L_{9}$ orthogonal array and $n=$ Total number of responses chosen in the experimentation.

The steps for weight calculation of each response is as follows.

1. Calculation of the sum of the grey relational coefficient in all data sequences for each response:

$$
D_{j}=\sum_{i=1}^{m} r_{i}(j), j=1,2, \ldots, n .
$$

2. Evaluation of the normalized coefficient:

$$
k=\frac{1}{\left(e^{0.5}-1\right) \times m}=\frac{1}{0.6847 \times m} .
$$

3. Calculation of the entropy of each response:

$$
\begin{gathered}
e_{j}=k \sum_{i=1}^{m} w_{e}\left(\frac{r_{i}(j)}{D_{j}}\right), j=1,2, \ldots, n, \\
w_{e}(x)=x e^{1-x}+(1-x) e^{x}-1 .
\end{gathered}
$$

4. Calculation of the sum of entropy:

$$
E=\sum_{j=1}^{n} e_{j}
$$


5. Calculation of the weight of each response:

$$
\begin{gathered}
w_{j}=\frac{1}{n-E} \cdot \frac{1}{\sum_{j=1}^{n} \frac{1}{n-E} \cdot\left[1-e_{j}\right]}, \\
j=1,2, \ldots, n .
\end{gathered}
$$

The sum of grey relational coefficients $D j, j=1$, $2 \ldots$ for both burr height and surface roughness average, have been calculated using equation 10 . The value of the normalized coefficient has been calculated using equation 11 . In the present case, $m=9$. Therefore, the evaluated value of the normalized coefficient becomes $k=0.1713$. The values of $\left(\frac{\boldsymbol{r}_{\boldsymbol{i}}(j)}{\boldsymbol{D}_{j}}\right)$ and $k * w_{e} *\left(\frac{r_{i}(j)}{D_{j}}\right)$ for burr height and surface roughness average have been depicted in Table 4.

Entropy of the responses has been calculated using equation 15; the values have been furnished in Table 5 . The sum of entropy $\mathrm{E}$ has been calculated using equation 16. The individual weights have been calculated using equation14. It has been found that both burr height and surface roughness average are equally important $w_{1}=w_{2}=0.5$ appropriately corresponds to case 1. Hence, multi objective optimization functional task has been converted into a single objective optimization problem using the combination of Taguchi methodology and grey relational theory. Higher is the value of grey relational grade, the corresponding input factor combination is said to be close to the optimal which shows A3B2C3. After determining the optimal setting of input parameters, confirmatory test has been conducted and found satisfactory results. On optimal level of setting of parameters, experimentally attained value of overall grey relational grade became more compared to Taguchi's prediction.

Tab. 4. Calculation of $k * w_{e} *\left(\frac{r_{i}(j)}{D_{j}}\right)$

\begin{tabular}{ccc}
\hline S. No. & Burr height & Surface roughness \\
\hline 1 & 0.0439 & 0.0263 \\
\hline 2 & 0.0313 & 0.0257 \\
\hline 3 & 0.0430 & 0.0305 \\
\hline 4 & 0.0306 & 0.0233 \\
\hline 5 & 0.0635 & 0.0594 \\
\hline 6 & 0.0336 & 0.1143 \\
\hline 7 & 0.0762 & 0.0286 \\
\hline 8 & 0.0361 & 0.0614 \\
\hline 9 & 0.0399 & 0.0610 \\
\hline
\end{tabular}

Tab. 5. Calculation of $e_{j}$ (entropy of each quality indexes)

\begin{tabular}{cc}
\hline \multicolumn{2}{c}{ Entropy of each response } \\
\hline Burr height & Surface roughness \\
\hline 0.3981 & 0.4305 \\
\hline
\end{tabular}

Tab. 6. Calculation of $w_{j}$ (weightage value of each quality characteristics)

\begin{tabular}{cc}
\hline \multicolumn{2}{c}{ Response weights } \\
\hline $\begin{array}{c}\text { Priority value of Burr } \\
\text { height }\left(w_{1}\right)\end{array}$ & $\begin{array}{c}\text { Priority value of Surface } \\
\text { roughness }\left(w_{2}\right)\end{array}$ \\
\hline 0.51378 & 0.48612 \\
\hline
\end{tabular}

\section{RESULTS AND DISCUSSIONS}

Discussion from results obtained through Taguchi experimental design and ANOVA (from Table 7) reveals that Spindle speed and feed rate are most influential input factors to optimize burr height but for surface roughness depth of cut and feed rates are identified significant parameters to optimize surface roughness during end milling of nickel based super alloy.

Tab. 7. ANOVA for Burr height $\left(F_{\text {table }}=19(2,2)\right.$ at $95 \%$ confidence level)

\begin{tabular}{ccccc}
\hline Parameter & DoF & Adj SS & Adj MS & F-Value \\
\hline A & 2 & 2.766514 & 1.38327 & $31.91^{*}$ \\
B & 2 & 1.328924 & 0.66447 & 15.33 \\
C & 2 & 7.436802 & 2.47895 & $57.18^{*}$ \\
Error & 2 & 0.000817 & 0.04335 & \\
Total & 8 & 14.62542 & & \\
\hline
\end{tabular}

Tab. 8. ANOVA for Surface roughness $\left(F_{\text {table }}=19(2,2)\right.$ at $95 \%$ confidence level)

\begin{tabular}{ccccc}
\hline Parameter & DoF & Adj SS & Adj MS & F-Value \\
\hline A & 2 & 0.020917 & 0.010458 & 12.81 \\
B & 2 & 0.048250 & 0.024125 & $29.54^{*}$ \\
C & 2 & 0.178161 & 0.059387 & $72.72^{*}$ \\
Error & 2 & 0.043412 & 0.000817 & \\
Total & 8 & 0.266356 & & \\
\hline
\end{tabular}

The effects of input parameters on data means of responses is observed from Fig. 6 reveals that input parameters under moderate level of rotational speed, high level of depth of cut and medium level of feed rate influence more on output responses i.e. increase of rotational speed, feed rate and depth of cut causes optimum values of burr height simultaneously.

The effects of input parameters on data means of responses is observed from Fig. 7 reveals that input parameters under lower level of rotational speed and depth of cut and medium level of feed rate influence more on output responses i.e. decrease of rotational speed and depth of cut and increase of feed rate causes optimum values of surface roughness. Also it is identified from ANOVA results $R-s q$ and $R-s q$ (pred) values are more than $90 \%$, shows that hypothesis is good agreement with selection and conducting experimental method. 
Results obtained from grey relational analysis by selecting three cases of weightage concludes that optimal setting of combination of input parameters to enhance the results drawn from Taguchi independently shown in Table 3.

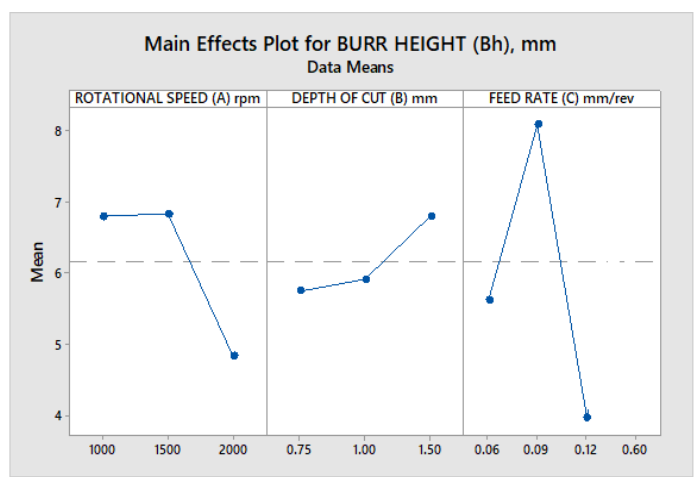

Fig. 6. Main effect plot for Burr height

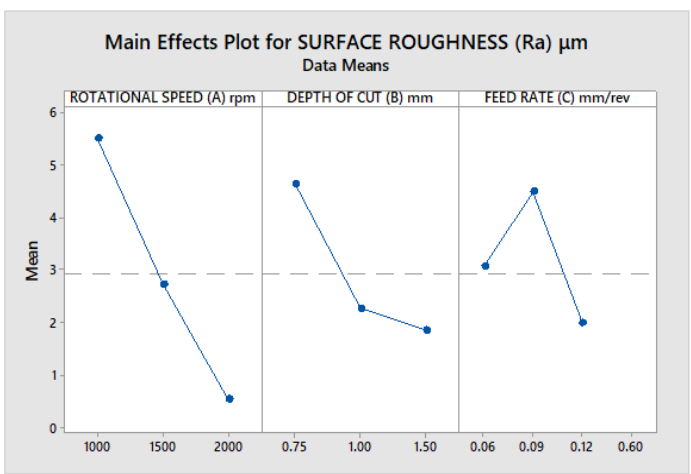

Fig. 7. Main effect plot for Surface Roughness

These have been evaluated from overall grey relational grades corresponding to each level and obtained optimal combination of machining parameters to optimize both burr height and surface roughness are A32B2C3 i.e. $2000 \mathrm{rpm}$ spindle speed, $1 \mathrm{~mm}$ depth of cut and $0.12 \mathrm{~mm} / \mathrm{rev}$ feed rate with 0.5 weightage of both responses could be provide better surface quality with good burr free assembly wherever machined components needs to be assemble. It has been observed from entropy measurement technique that the optimal combination of parameters is sensitive to the individual response weights which is almost equivalent with weightage considered in grey relational method.

However, assignment of these weights greatly depends on the decision maker. Therefore, it seems to be a need to propose a means which can estimate the output response weights mathematically so as to evade disparity of optimal setting of input parameters due to various setting of output response priorities defined by the decision maker. In sight of the above truth, the study recommends the relevance of entropy measurement method for orderly estimations and tactical assessment of individual response weights.

Surface contour graphs are plotted in 2D plane using MINITAB@17 software for each output and input parameters. In contour graphs, different colours or levels of gray scale, labelled contour lines, or both distinguish ranges of $Z$ values. Figure $8 \mathrm{a}-\mathrm{c}$ and Figure 9a-c depicts that minimum burr height and surface roughness was found when the feed rate kept moderately and depth of cut are average with all the chosen level of parameters and 0.5 weightage equally for both responses. Also, the contour graphs reveals that minimum burr height was found when the spindle speed $1500 \mathrm{rpm}$ and $2000 \mathrm{rpm}$ and depth of cut as well as possible put minimum value with all the chosen level of factors.

a)

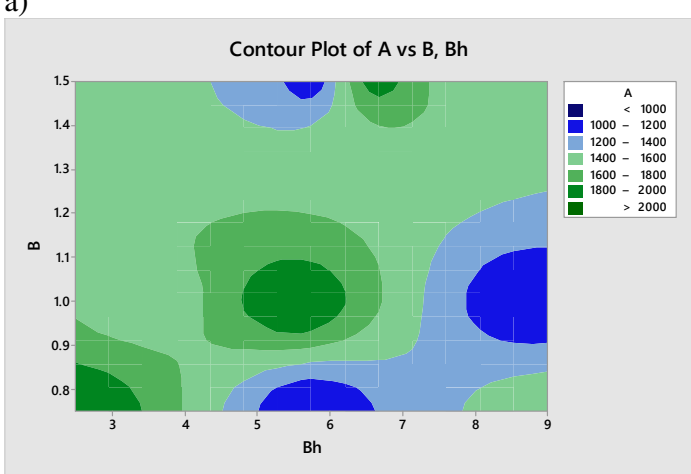

b)

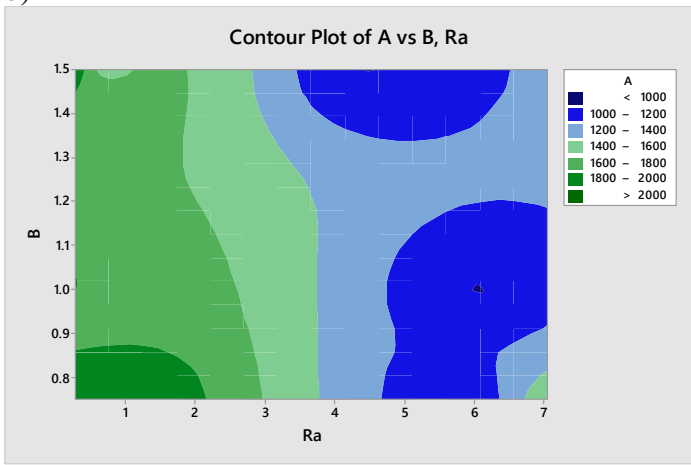

c)

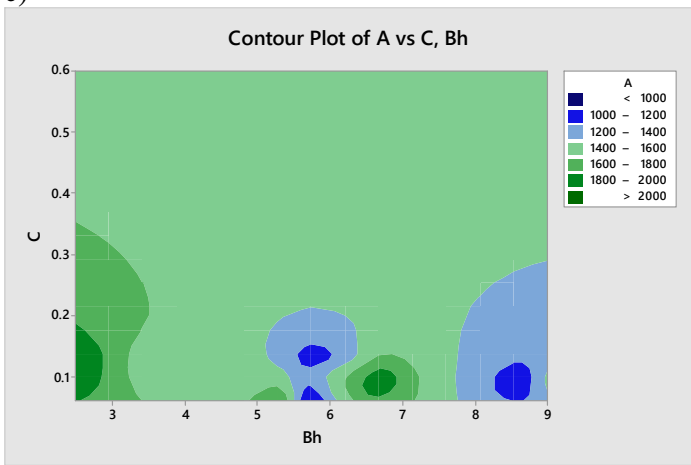

Fig. 8. Contour plots against with influence of input parameters on output responses- part $1 / 2$ 
a)

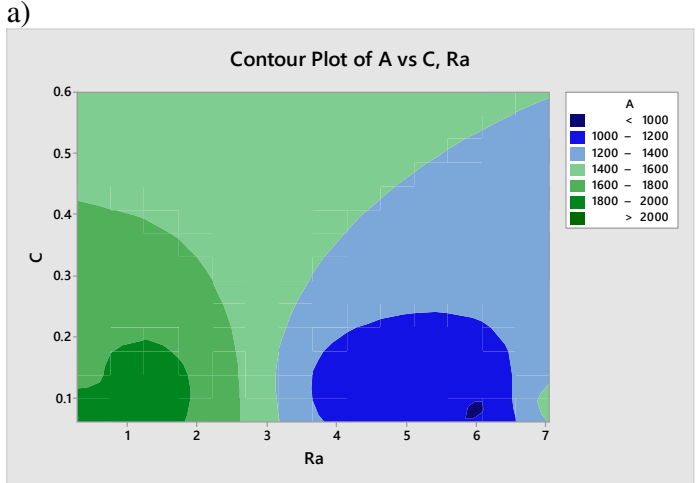

b)

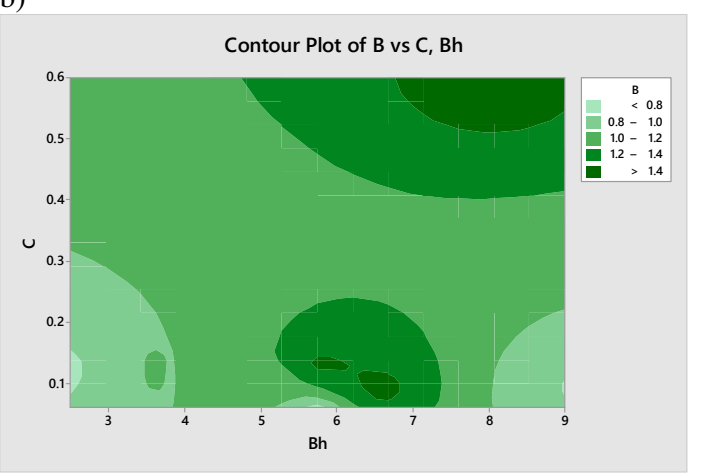

c)

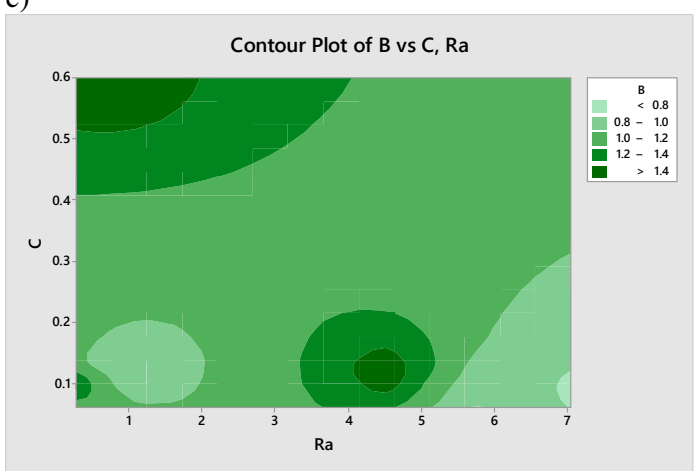

Fig. 9. Contour plots against with influence of input parameters on output responses- part $2 / 2$

\section{CONCLUSIONS}

The earlier studies deals with multi criterion optimization of $\mathrm{CNC}$ end milling by pertaining grey based Taguchi approach. Application of grey relation theory is suggested to alter multiple objectives into a single objective function (overall grey relational grade) to make it possible to investigate the influence of process parameters using Taguchi method. In conventional Taguchi technique not able to solve a multi objective optimization problem may not be solved especially in the case of design of experiments. So, in the present paper Taguchi method has been integrated with grey relation theory. Entropy measurement technique has been suggested to compute individual output response weights of the process according to their relative priority. The combination of entropy measurement with grey based Taguchi method was utilized in the present study proficiently implemented for continuous quality enhancement during a process not only $\mathrm{CNC}$ end milling but also any other conventional machining operations where multiple objectives come under consideration. In the said above paragraphs, it has been assumed that all responses are independent i.e., uncorrelated. But in the actual practice this assumption may diverge. How to handle this situation appears truly a challenging job. There exists adequate scope to prolong a research in this particular direction. Furthermore, interaction effect of machining parameters may also be considered in future scope of work.

\section{Nomenclature}

\section{Symbols}

$A$ - Rotational Speed, rpm

$B$ - Depth of Cut, mm

$C$ - Feed Rate, $\mathrm{mm} / \mathrm{rev}$

$B h$ - Burr height, mm

$R_{a}$ - Surface Roughness, $\mu \mathrm{m}$

$k$ - Normalized Coefficient

$W$ - Entropy function

E - Sum of Entropy

\section{Greek letters}

$\xi-$ Distinguishing Coefficient

$\gamma \quad-$ Grey relational grade

\section{References}

1. Alauddin, M., El Baradie, M. A., \& Hashmi, M. S. J. (1996). Optimization of surface finish in end milling Inconel 718. Journal of Materials Processing Technology, Vol. 56(1-4), pp 54-65

2. Hajiahmadi, S. (2019). Burr size investigation in micro milling of stainless steel 316L. International Journal of Lightweight Materials and Manufacture, Vol. 2, No.4, pp 296-304

3. Vipindas, K., Kuriachen, B., \& Mathew, J. (2019). Investigations into the effect of process parameters on surface roughness and burr formation during micro end milling of TI-6AL-4V. The International Journal of Advanced Manufacturing Technology, Vol. 100 (5-8), pp1207-1222

4. Shokrani, A., Dhokia, V., \& Newman, S. T. (2016). Investigation of the effects of cryogenic machining on surface integrity in CNC end milling of Ti-6Al-4V titanium alloy. Journal of Manufacturing Processes, Vol. $21,172-179$

5. Masmiati, N., \& Sarhan, A. A. (2015). Optimizing cutting parameters in inclined end milling for minimum surface residual stress- Taguchi approach. Measurement, Vol. 60, pp 267-275

6. Ulutan, D., \& Ozel, T. (2011). Machining induced surface integrity in titanium and nickel alloys: A review. International Journal of Machine Tools and Manufacture, Vol. 51, No.3, pp 250-280

7. Luo, M., Luo, H., Zhang, D., \& Tang, K. (2018). Improving tool life in multi-axis milling of Ni-based superalloy with ball-end cutter based on the active cutting edge shift strategy. Journal of Materials Processing Technology, Vol. 252, pp 105-115 
8. Singh, G., Gupta, M. K., Mia, M., \& Sharma, V. S. (2018). Modeling and optimization of tool wear in MQL-assisted milling of Inconel 718 superalloy using evolutionary techniques, The International Journal of Advanced Manufacturing Technology, Vol. 97 (1-4), pp 481-494

9. Thellaputta, G. R., Chandra, P. S., \& Rao, C. S. P. (2017). Machinability of nickel based super alloys: a review. Materials Today: Proceedings, Vol. 4, No. 2, pp 3712-3721

10. Karidkar, S. S., \& Dabade, U. A. (2016). Experimental Investigation and Optimization of Response Variables in WEDM of Inconel-718, In IOP Conference Series: Materials Science and Engineering, Vol. 114, No. 1, pp 1-9. IOP Publishing

11. Manohar, M., Joseph, J., Selvaraj, T., \& Sivakumar, D. (2013). Application of Box Behnken design to optimize the parameters for turning Inconel 718 using coated carbide tools. International Journal of Scientific \& Engineering Research, Vol. 4, No.4, pp 620-644

12. Janos, M., \& Mrkvica, I. (2012). Milling Possibilities of Material Inconel 718. Journal of Manufacturing and Industrial Engineering, Vol. 11, No.4, pp 16-18

13. Lu, X., Wang, F., Wang, X., Lu, Y., \& Si, L. (2017). A surface roughness prediction model using response surface methodology in micro-milling Inconel 718. International Journal of Machining and Machinability of Materials, Vol. 19, No.3, pp 230-245

14. Sreenivasulu, R., Hussain, S. H., \& Vineeth, R. V.(2018). Taguchi Based Experimental Studies on Surface Roughness and Burr Formation during End Milling of Inconel 718. AKGEC International Journal of Technology, Vol. 9, No. 1, pp 65-71

15. Hashimura, M., Hassamontr, J., \& Dornfeld, D. A. (1999). Effect of in-plane exit angle and rake angles on burr height and thickness in face milling operation, Journal of Manufacturing Science and Engineering, Vol. 121, No. 1, pp13-19

16. Niknam, S. A., \& Songmene, V. (2015). Milling burr formation, modeling and control: a review. Proceedings of the Institution of Mechanical Engineers, Part B: Journal of Engineering Manufacture, Vol. 229, No. 6, pp 893-909

17. Niknam, S. A., \& Songmene, V. (2013). Modeling of burr thickness in milling of ductile materials. The International Journal of Advanced Manufacturing Technology, Vol. 66 (9-12), pp 2029-2039

18. Julong, D. (1989). Introduction to grey system theory. The Journal of grey system, Vol. 1, No. 1, pp 1-24

19. Sreenivasulu, R., Rao, C. S., \& Ravindra, K (2019). Grey based Taguchi approach integrated with entropy measurement for optimization of surface roughness and delamination damage factor during end milling of GFRP composites, International Journal of Modern Manufacturing Technologies, Vol. XI, No. 2, pp 133-141

20. Sreenivasulu, R., Rao, C., \& Ravindra, K. (2020). Effect of thrust and torque exerted during drilling to optimize exit burr height and thickness by choosing variable drill bit geometry: A simplified theoretical model approach. International Journal of Data and Network Science, Vol. 4, No. 1, pp 43-56

\section{Biographical notes}

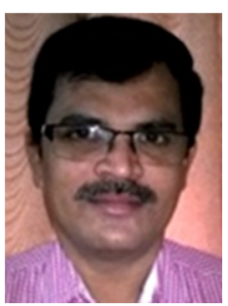

Reddy Sreenivasulu is Assistant Professor in the department of Mechanical Engineering, R.V.R \& J.C College of Engineering (A) Guntur, Andhra Pradesh, India. He received $\mathrm{Ph} . \mathrm{D}$ degree from Andhra University, Visakhapatnam in the year 2018, M.E degree from the Osmania University, Hyderabad in the year 2003 and B.Tech Mechanical Engineering from Regional Engineering College Warangal in the year 1997. He has 19 years of teaching experience. His area of research interest includes design of experiments, robotics, modeling and analysis of manufacturing processes and optimization. He has published more than 60 research papers in the international journal/conferences proceedings and acting as a reviewer for a peer reviewed referred journals.

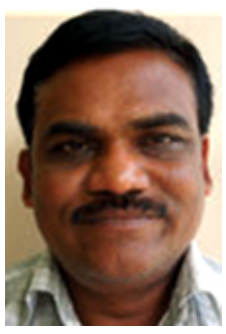

Ch. Srinivasa Rao is a professor in Mechanical Engineering Department of Andhra University College of Engineering, Visakhapatnam. $\mathrm{He}$ guided more than 10 research scholars and several Post Graduate students in various domains of Mechanical Engineering. He published more than 150 national and International journals with high eminence. 